\title{
Axial Load Monitoring for Concrete Columns Using a Wearable Smart Hoop Based on the Piezoelectric Impedance Frequency Shift: A Feasibility Study
}

\author{
Yabin Liang $\mathbb{D}^{1,2}$ Zhicheng Ye, ${ }^{1}$ and Qian Feng $\mathbb{D}^{1,2}$ \\ ${ }^{1}$ Hubei Key Laboratory of Earthquake Early Warning, Institute of Seismology, CEA, Wuhan, Hubei 430071, China \\ ${ }^{2}$ Wuhan Institute of Earthquake Engineering Co., Ltd., Wuhan, Hubei 430071, China \\ Correspondence should be addressed to Qian Feng; qfengwh@foxmail.com
}

Received 12 October 2019; Accepted 24 February 2020; Published 13 June 2020

Academic Editor: Liborio Cavaleri

Copyright (c) 2020 Yabin Liang et al. This is an open access article distributed under the Creative Commons Attribution License, which permits unrestricted use, distribution, and reproduction in any medium, provided the original work is properly cited.

Concrete columns are critical in supporting the weight of an entire structural frame and also play a key role in force transferring among structural members. Therefore, integrity of the columns, especially their axial load bearing capacity, directly affects the stability and safety of the entire structure. In this study, a wearable smart hoop is designed to monitor the axial load of the concrete columns. The smart hoop measures the shift in impedance frequency of its integrated piezoelectric transducer and correlates the frequency to the structural state of the column. In order to validate the feasibility of the smart hoop, an experiment on two concrete columns with different dimensions is carried out. The smart hoop is installed on each column. Then, an increasing axial load was applied onto the specimen, and the admittance of the PZT patch is acquired under different load levels by using an impedance analyzer. Finally, frequencies corresponding to the peak and trough in the susceptance of the admittance signal are collected as the monitoring index to estimate the axial load variation on the specimen. The experimental results demonstrated a downward shift in frequency corresponding to an increase of axial load. The results validate the feasibility of the wearable smart hoop in monitoring axial load for concrete columns and show potential for retrofit on existing columns.

\section{Introduction}

Concrete columns are important load transferring components and play a key role in the structural integrity of most concrete buildings. The structural health of the columns directly influences the stability and safety of the entire structural system. Knowledge of a column's axial load bearing capacity can help determine the integrity of the structural system and has therefore been the subject of attention for many researchers. For example, Ferrotto et al. conducted a series of experimental investigation and theoretical analysis to study the compressive behavior of RC columns strengthened by steel or fiber-reinforced polymer (FRP) jackets when subjected to the axial preload [1-4].

In recent years, numerous research efforts in the area of structural health monitoring (SHM) have been conducted to improve our ability to assess structural integrity. For instance, efforts have been devoted to detect structural damage, identify service conditions, and evaluate the residual life of concrete structures. In order to overcome the limitations on conventional manual inspection, which is time-consuming and costly, research efforts have focused on monitoring techniques that aim to extract the most information with the least amount of skilled human intervention. Such techniques include the measurement of acoustic emission (AE), which involves the recording of elastic waves generated by the release of localized internal energy from within the host structure. An advantage for AE monitoring is that the position of the developing cracks can be determined and the entire structure can be tested without interrupting the performance of the structure [5-7]. On the other hand, visual monitoring is speedy and inexpensive and has thus become the most popular approach to detecting exterior defects in concrete structures $[8,9]$. Terrestrial laser 
scanning (TLS), which generates a point cloud that estimates the topology of an object's surface, was also utilized to detect defects on the surfaces of concrete structures. TLS has demonstrated the ability to simultaneously localize and quantify spalling defects [10]. Recent years have seen the introduction of smart materials and structures, such as fiber optic sensors and piezoelectric materials, for the SHM of concrete structures. Fiber optic fiber Bragg grating (FBG) sensors have in particular received much attention due to their high precision and small size. FBGs are also resistant to corrosive environments and are low cost per sensor. FBGs have, for example, been embedded in concrete for deformation monitoring and traffic load assessment in bridges [11-14]. At the same time, piezoelectric transducers have been readily accepted for the concrete structural health monitoring due to their advantages of active sensing, low cost, rapid response, availability in different geometries, and simplicity of implementation [15-20]. Piezoelectric transducers, which are often composed of lead zirconate titanate (PZT), experience a measurable change in electromechanical impedance (EMI) when local mechanical conditions change, such as due to damage in the structure hosting the transducer. EMI technique can be performed using a single transducer and is noninvasive, leading to an increasing popularity for use in SHM over the past decades.

Changes in the EMI of a piezoelectric transducer can be quantified by the root-mean-square deviation (RMSD) of the impedance signatures. The RMSD has been used as an index to quantitatively evaluate damage in a variety of structures [21-24]. The frequency shift of an acquired impedance signal was also utilized as a metric to estimate the health of the structure. For example, Ong et al. [25] developed a dynamic impedance model to investigate the influence of in situ stress on the dynamic and electromechanical response of surface bonded piezoelectric transducers. The model helped discover that the natural frequency of the transducers shifts in the presence of in situ stress. Lim and Soh [26] reported a series of experimental, analytical, and numerical studies that investigated the effect of axial load and fixed boundary conditions on the admittance signatures and demonstrated that the tensile stress induces stiffening effect and results in the change of the resonance frequency of the peaks in the admittance signature spectrum. Shao et al. [27] and Liang et al. [28], respectively, monitored the bolt looseness and the load variation of pin connected structures via measurement of impedance frequency shift. Wang et al. [29] demonstrated that when the host structure is subjected to a tensile stress, the resonances in the admittance spectrum of a PZT transducer increase linearly.

One goal of piezo-based SHM research is to understand the influence of axial force, as experienced by the host structure, on the probing signals of the transducers. Liu et al. [30] experimentally investigated the effects of axial compressive loading on the amplitude and velocity of active sensing signals generated and received by embedded piezobased smart aggregate (SA) transducers. The experimental results demonstrated that the amplitude attenuation is dependent on both frequency and load history, while the velocity is highly stress-dependent. Wang et al. [31] investigated the influence of compressive loads on EMI-based damage monitoring of standard concrete cube specimens at five different steel fiber contents. The EMI signals were collected from an embedded SA sensor, and the repeating test results showed that there is a great linearity between the RMSD based index and the applied loading. Both studies $[26,27]$ utilized embedded SA sensors to realize the load monitoring or damage detection; however, SAs cannot be practically embedded in the already existing concrete structures.

Thus, this study simultaneously explores the feasibility of SHM through the wearable device using the piezoelectric transducers and the use of high-frequency range $(\mathrm{MHz})$ impedance shifts for axial load monitoring in concrete columns, which has not yet been reported in the literature. Specifically, this study investigates the following:

(1) Design and assembly of a wearable smart hoop, which includes a piezoelectric sensor bonded onto a polished face of the fastening bolt and the theoretical derivation of the relationship between the axial load on the host structure and the internal force of the smart hoop

(2) Experimental investigation of the relationship between the piezoelectric impedance frequency shift and the applied axial load on the concrete columns

(3) Quantitative evaluation of the axial load applied on the concrete specimen based on the load monitoring index

In this research, two concrete columns with different dimensions are poured and tested in the laboratory. In the experiment, increasing axial loads are applied on columns using a universal hydraulic testing machine. A wearable smart hoop is tightened around the tested column and a precision impedance analyzer measures the impedance signatures of the PZT bonded on the hoop. In addition, the frequencies corresponding to the peak and trough of the acquired admittance signature under different load conditions directly serve as indicators for the load monitoring index. The results facilitate a discussion on the feasibility of the proposed smart hoop to be used for monitoring of concrete columns.

\section{Detection Principle}

2.1. Electromechanical Impedance (EMI). The impedancebased health monitoring method was first conceptualized by Liang et al. [32]; then subsequent applications of the EMI method were reported by several other researchers [33-38]. This technique takes full advantages of the unique electromechanical properties of the piezoelectric patches, which have dual functions as sensors and actuators, simultaneously. The interactive electromechanical coupling mechanisms provide the piezoelectric patches the possibility to response, within the sensing frequency range, to even the slightest alterations in the frequency response functions (FRF) of its host structure; thus the structural health can be directly detected and monitored. 
For the EMI technique, the electromechanical coupling between the PZT patches and the host structure can be conceptually represented by an ideal $1 \mathrm{D}$ electromechanical system $[32,39]$. Assuming a surface-bonded PZT patch is attached to one end of the host structure represented by a single degree-of-freedom (DOF) system (i.e., a spring-massdamper system), the other end of the PZT patch is fixed. Then, a harmonic input voltage $V(\omega)$ at an angular frequency $\omega$ is applied on the PZT patch and thus induces an axial vibration. Therefore, the electric admittance $Y(\omega)$, as an inverse of the electrical impedance $Z(\omega)$, of the PZT patch is a combined function of the mechanical impedance of the PZT patch $\mathrm{Za}(\omega)$ and that of the host structure $Z \mathrm{~s}(\omega)$ and can be expressed in the following equation:

$$
Y(\omega)=\frac{I}{V}=i \omega a\left(\bar{\varepsilon}_{33}^{T}(1-i \delta)-\frac{Z_{s}(\omega)}{Z_{s}(\omega)+Z_{a}(\omega)} d_{3 x}^{2} \widehat{Y}_{x x}^{E}\right),
$$

where $V$ and $I$ denote the input voltage and the output current of the PZT patch, respectively; $a$ is the geometric constant of the PZT patch; $Y_{x x}^{E}, \varepsilon_{33}^{T}$, and $\delta$ are the complex Young's modulus within zero electric field, the dielectric constant at zero stress, and the dielectric loss tangent of the PZT patch, respectively; $d_{3 x}$ is the piezoelectric coupling constant in the arbitrary $x$ direction at zero stress.

The EMI technique, which can measure changes in the local impedance with high frequency and is very sensitive to local damage, can be employed for development of a nondestructive damage detection and structural health monitoring system. Changes in the mechanical properties of the host structure can be measured by monitoring the changes in the output of the EMI function, as indicated in (1).

2.2. Piezoelectric-Based Smart Hoop. In this study, a wearable smart hoop with the piezoelectric transducer is designed and applied to monitor the axial load variation of concrete columns, as shown in Figure 1. The smart hoop consists of a steel hoop, a fastening bolt, and a rectangular PZT patch bonded on a polished face of the fastening bolt. By fastening or loosening the bolt, the diameter of the smart hoop can be adjusted to adapt to the existing columns with different dimensions.

As shown in Figure 2(a), when the smart hoop is installed onto a cylindrical concrete column with radius of $R$ and an axial load $F$ is applied to the top surface of the column, then the loading status of the smart hoop can be analyzed. Assuming the force applied on the smart hoop due to the effect of the axial force $F$ can be regarded as a uniform pressure $P_{0}$, as shown in Figure 2(b), thus a positive correlation between these two parameters can be summarized as

$$
P_{0} \propto F \text {. }
$$

It should be noted that the concrete column always expands along the radial direction in response to a compressive axial force, while the stress and deformation of the concrete along the height are actually quite nonuniform due

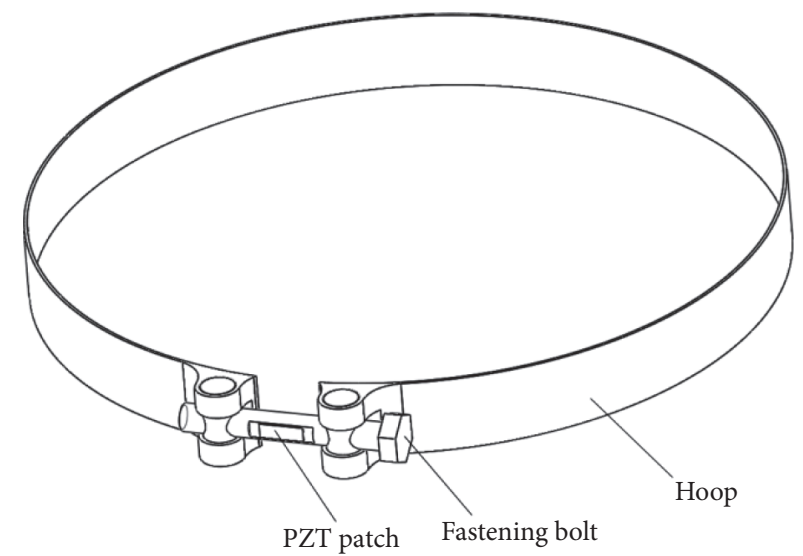

Figure 1: Schematic of the smart hoop.

to the cyclo-hoop effect $[40,41]$. The uniform pressure $P_{0}$ of the smart hoop is directly related to the installation position and is very different along the height of the columns. But the cyclo-hoop effect does not influence the effectiveness of (2) that the pressure $P_{0}$ increases with the applied axial load $F$ in this study.

For a concrete column, the pressure $P_{0}$ exerted on the smart hoop increases with the axial load $F$ on the column. The tension through the fastening bolt (denoted as $F_{0}$ in Figure 2(b)) can be expressed as

$$
F_{0}=\frac{1}{2} \int_{0}^{\pi} d f=\frac{1}{2} \int_{0}^{\pi} R \cdot d \theta \cdot b \cdot P_{0} \cdot \operatorname{Sin} \theta=R b P_{0},
$$

in which $F_{0}$ is the tension of the fastening bolt, $P_{0}$ is the pressure applied on the smart hoop along the radial direction, $R$ denotes the radius of the concrete column, and $b$ is the width of the smart hoop. This equation indicates that there is a proportional relationship between the tension $F_{0}$ and the applied pressure $P_{0}$ on the smart hoop.

Substituting (3) into (2), thus $F_{0}$ is positively correlated to the axial load $F$, or in other words,

$$
F_{0} \propto F \text {. }
$$

The above analysis suggests that, with an increase of the axial load on the column, the reaction force between the smart hoop and the column also increases, which in turn increases the tension of the fastening bolt. As described in Section 2.1, physical changes in the fastening bolt due to applied tension can be detected by analyzing the impedance signatures of the PZT patch bonded on the bolt.

\section{Pretest Investigation}

In order to elucidate the relationship between the applied load on the host structure and the loading monitoring index via measurement of the piezoelectric impedance frequency shift, a simplified test is first conducted prior to the experimental investigation for the smart hoop, as shown in Figure 3. A steel plate $(300 \mathrm{~mm} \times 15 \mathrm{~mm} \times 1 \mathrm{~mm})$ with a surface bonded PZT patch $(20 \mathrm{~mm} \times 7 \mathrm{~mm} \times 0.5 \mathrm{~mm})$ is axially tensioned by a universal testing machine. Figure 4 presents the experimental setup. 


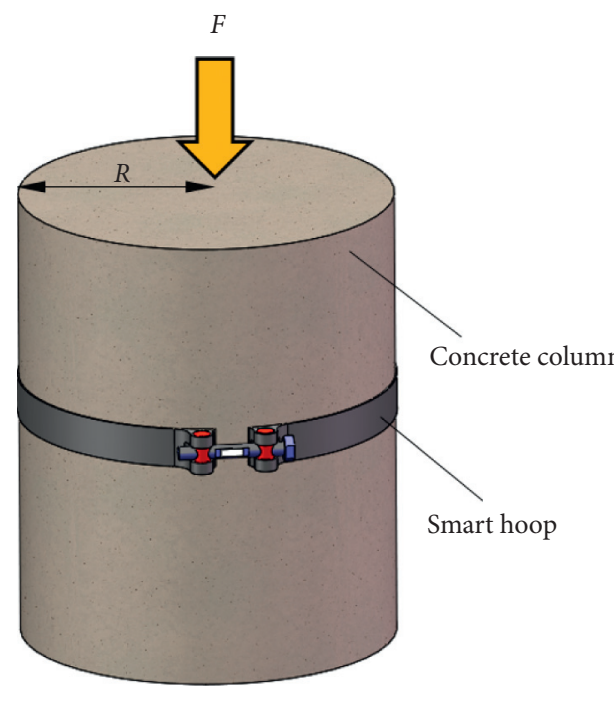

(a)

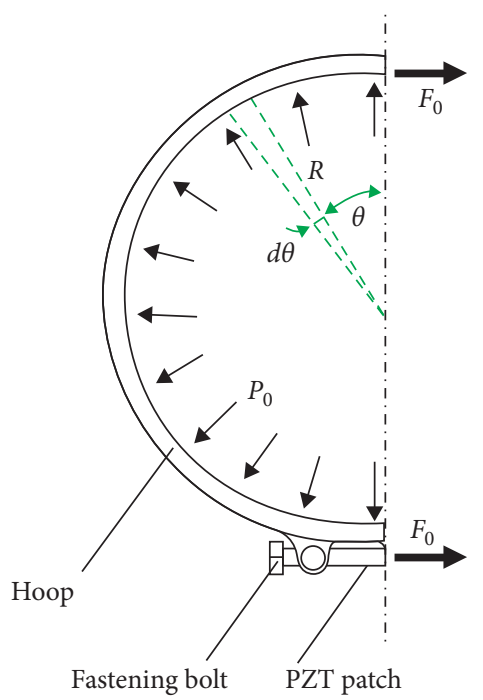

(b)

FIGURE 2: Loading diagram when the column is subjected to the axial load: (a) the column installed with the smart hoop; (b) the cutaway view for the smart hoop.

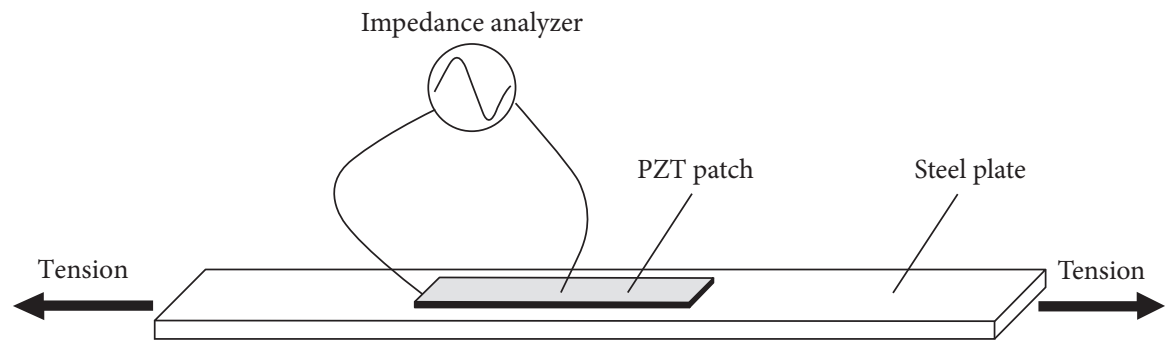

Figure 3: Schematic diagram of the simplified test.

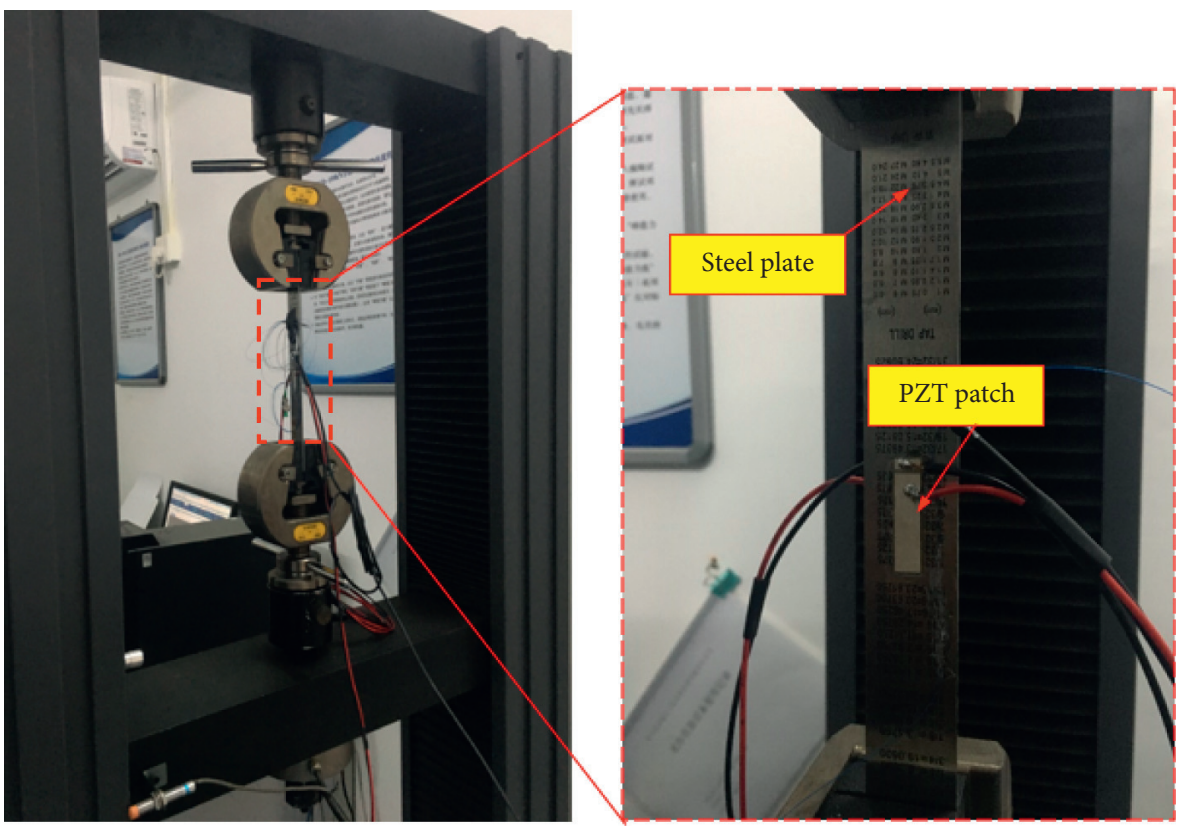

FIgURE 4: Experimental setup for tensioning the steel plate. 
The lower frequency range $(<1 \mathrm{MHz})$ of the EMI signal is often used in the literature to detect changes in the structural integrity because in the lower frequency range, the EMI signal is more sensitive to slight changes and incipient damage $[22,42,43]$. Recently, researchers have begun to look towards the high-frequency band $(\mathrm{MHz})$ to monitor the stress state of structures, and the experimental investigation had successfully provided interesting results [27, 29]. Therefore, a wide frequency scan of the impedance signal in a high-frequency range $(\mathrm{MHz})$ is conducted in the study by an impedance analyzer (WKE 6500B, Wayne Kerr Electronics Co., UK) and the measured result is shown in Figure 5. Thus, frequency ranges between $2000 \mathrm{kHz}$ and $2150 \mathrm{kHz}$ and $3300 \mathrm{kHz}$ and $3420 \mathrm{kHz}$ are selected as the impedance-sensitive range in this study.

It should be noted that several researchers $[29,44]$ had demonstrated that the susceptance signature (i.e., the imaginary part of the admittance) may be superior to the conductance signature (i.e., the real part of the admittance) for monitoring in situ stress in the host structure. Therefore, in this study, the imaginary part of the admittance signal under these two selected frequency range is acquired by the impedance analyzer under different load conditions, and the test results are shown in Figure 6-9.

Figures 6-9 show that an increase of the tension applied on the steel plate leads to a significant downward (i.e., towards the left) frequency shift for the admittance signatures of the PZT patch surface bonded on the plate. In addition, the monitoring indices (i.e., the frequencies corresponding to the wave peak and trough of the signal) consistently decrease with the increasing tension applied on steel plate. Therefore, the above results of this simplified test demonstrate that measurement of the impedance frequency shift can reveal the relationship between the applied load on the host structure and the corresponding monitoring indices. The simple test showed that increasing tension on the host structure directly induced a downward shift in the admittance signal of the PZT patch. The frequencies of the wave peak and trough also decrease with the increasing tension applied on the structure. Knowledge of this relationship will help to describe and explain the following experimental investigation results for the smart hoop.

\section{Experimental Setup and Procedures for the Wearable Smart Hoop}

Based on the above theoretical analysis and the simplified test, an axial compression test is performed on two cylindrical columns equipped and installed with the wearable smart hoop to validate the monitoring capabilities of the smart hoop. The piezoelectric impedance frequency shift is measured to quantitatively evaluate the loading variation for each column.

4.1. Concrete Column and Smart Hoop. The dimensions of the columns are $\varphi 150 \mathrm{~mm} \times 300 \mathrm{~mm} \quad(\# 1)$ and $\varphi 185 \mathrm{~mm} \times 200 \mathrm{~mm}(\# 2)$, as shown in Figure 10. For the proposed wearable smart hoop, a rectangular PZT-5
$(20 \mathrm{~mm} \times 7 \mathrm{~mm} \times 0.5 \mathrm{~mm})$ patch is bonded on a polished face of the fastening bolt using the epoxy. By adjusting the fastening bolt, the smart hoop is tightened at the midheight of the columns.

4.2. Experimental Setup. The instrumental setup is shown in Figure 11. The admittance signatures of the PZT patch on the smart hoop are measured by a precision impedance analyzer (WK6500B, Wayne Kerr Electronics Co., UK) over $2490 \mathrm{kHz}$ to $2500 \mathrm{kHz}$ for column $\# 1$ and $2450 \mathrm{kHz}$ to $2470 \mathrm{kHz}$ for column \#2. The data is transmitted from the impedance analyzer to be stored in the laptop via a LAN connection for the further postprocessing. A $1000 \mathrm{kN}$ capacity universal hydraulic testing machine is used to apply the axial compressive load on the columns, as shown in Figure 12. For column \#1, axial loads are applied from 0 to $440 \mathrm{kN}$ in increments of $40 \mathrm{kN}$, and for column \#2, the loads increase from 0 to $650 \mathrm{kN}$ in increments of $50 \mathrm{kN}$. The axial load was applied onto the top surface of the concrete specimen by the hydraulic testing machine with a load rate of $0.5 \mathrm{kN} / \mathrm{s}$. For each loading level, the axial force lasted $360 \mathrm{~s}$, and the EMI admittance signatures of the PZT patches are acquired using the impedance analyzer.

\section{Experimental Results}

5.1. Test Results for Column \#1. The sensitivity of the impedance-based health monitoring technique is closely related to the selected frequency range. Prior to the test, the PZT patches on the host structure are scanned over from $1 \mathrm{kHz}$ to $5 \mathrm{MHz}$ in order to select a suitable frequency range for acquiring the impedance signatures, as shown in Figure 13. Subsequently, the frequency range, from $2490 \mathrm{kHz}$ to $2500 \mathrm{kHz}$, is selected since a significant wave peak in the imaginary part of the admittance signature is covered in this range.

Figure 14 presents the imaginary part of the admittance signatures at different load levels for the specimen \#1, and from the figure, it can be observed that an increase of the axial load applied on column \#1 leads to a significant downward shift in the impedance peak frequency. In this study, the frequencies at which the peak and trough of the admittance signal occur serve as the loading monitoring index. Figure 15 shows that these monitoring indices consistently decrease with the increasing axial loads for column \#1. On the other hand, it is also observed that the frequency shift in the ranges of the initial $(0 \mathrm{kN})$ to $80 \mathrm{kN}$ and the $360 \mathrm{kN}$ to $440 \mathrm{kN}$ has a more significant decline than other load situations, as shown in Figures 14 and 15. This phenomenon may be caused by the redistribution of the internal force for the steel smart hoop during the experiment. At the beginning, the interface contact between the hoop and the RC column becomes tighter very quickly in the initial load conditions (i.e., from $0 \mathrm{kN}$ to $80 \mathrm{kN}$ ) with the increase of the applied axial load, and then the contact reaches its stabilization stage (i.e., from $80 \mathrm{kN}$ to $360 \mathrm{kN}$ ), which induces the impedance frequency shift changes relatively smoothly. At last, with the increase of the applied load, it is predicted that 


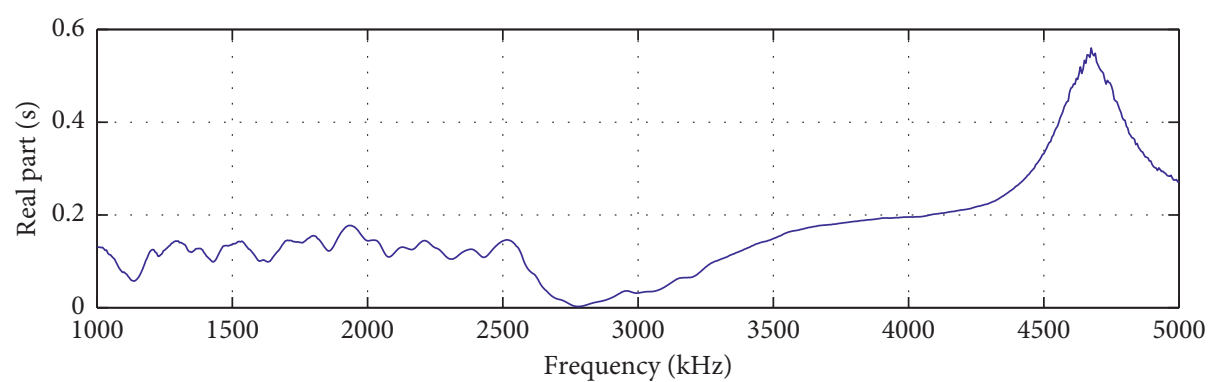

(a)

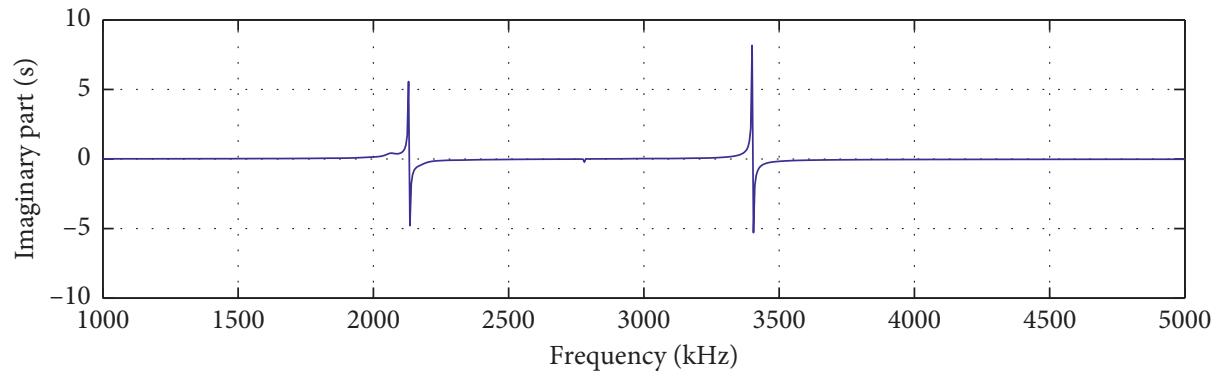

(b)

Figure 5: Scanned results for the additional experiment.

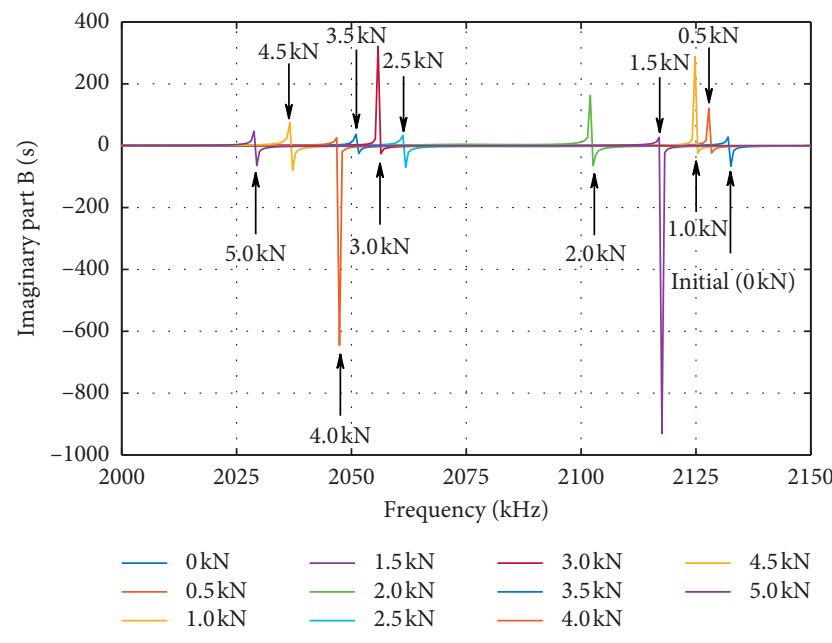

Figure 6: Admittance (imaginary part) signatures at different load conditions between $2000 \mathrm{kHz}$ and $2150 \mathrm{kHz}$ excitation.

the concrete in the weakness area of the column reaches its ultimate bearing capacity and becomes break and spalling, which finally induces the redistribution of the internal force of the concrete column and the smart hoop. In this situation (i.e., from $360 \mathrm{kN}$ to $440 \mathrm{kN}$ ), the frequency shift also presents a significant drop as shown in the figures. It should be noted that further research is needed if more underlying cause is required. Due to the space limitation, no more discussion is presented in this study.

5.2. Test Results for Column \#2. In order to further validate the feasibility of the smart hoop, the axial test is repeated on column \#2. As with column \#1, a wide frequency swept test

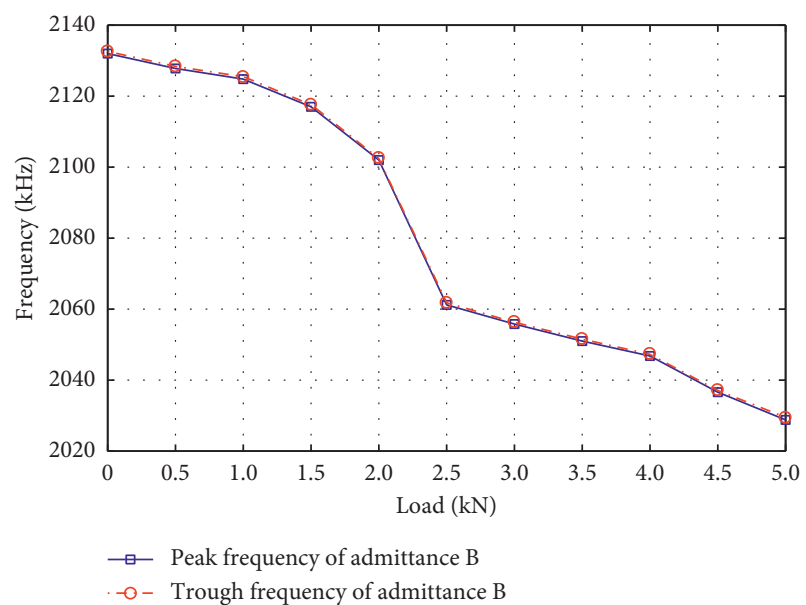

FIGURE 7: Frequencies corresponding to the peak and trough of the admittance signature between $2000 \mathrm{kHz}$ and $2150 \mathrm{kHz}$ excitation.

from $1 \mathrm{kHz}$ to $5 \mathrm{MHz}$ is conducted to select the suitable frequency range to interrogate the smart hoop after the smart hoop has been installed onto the specimen. Figure 16 shows the scan result of the admittance signature for column $\# 2$. As can be seen in the figure, the sensitive frequency range is situated between $2450 \mathrm{kHz}$ and $2470 \mathrm{kHz}$. Figure 17 presents the acquired admittance (imaginary part) signatures under the 14 different load conditions from the initial condition $(0 \mathrm{kN})$ to $650 \mathrm{kN}$, at which the specimen broke. As with the first test, a similar phenomenon can be observed in which the frequency of the admittance signals shifted leftwards with the increase of the axial load. Figure 18 shows the change of the monitoring indices (i.e., frequencies of the peaks and troughs) as the load changes. The experimental results for columns $\# 1$ and $\# 2$ share a similar response to 


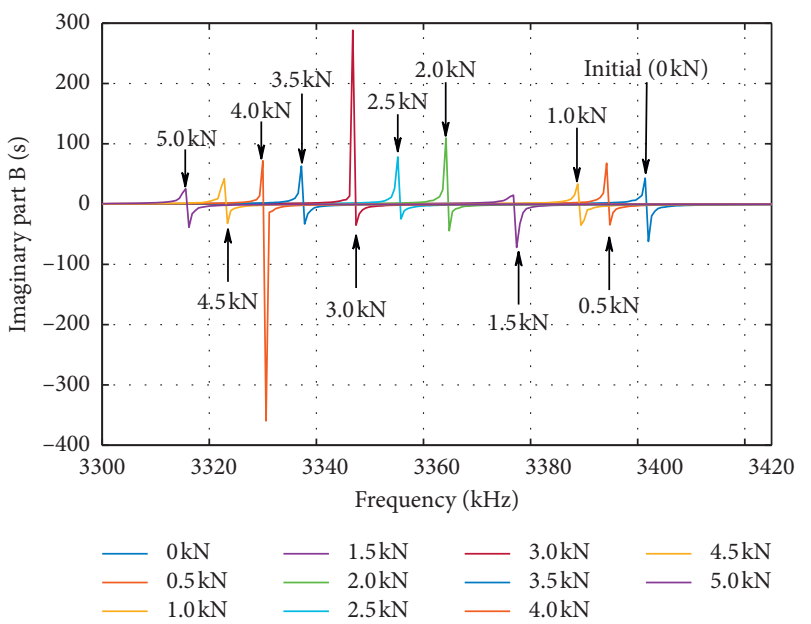

FIgure 8: Admittance (imaginary part) signatures at different load conditions between $3300 \mathrm{kHz}$ and $3420 \mathrm{kHz}$ excitation.

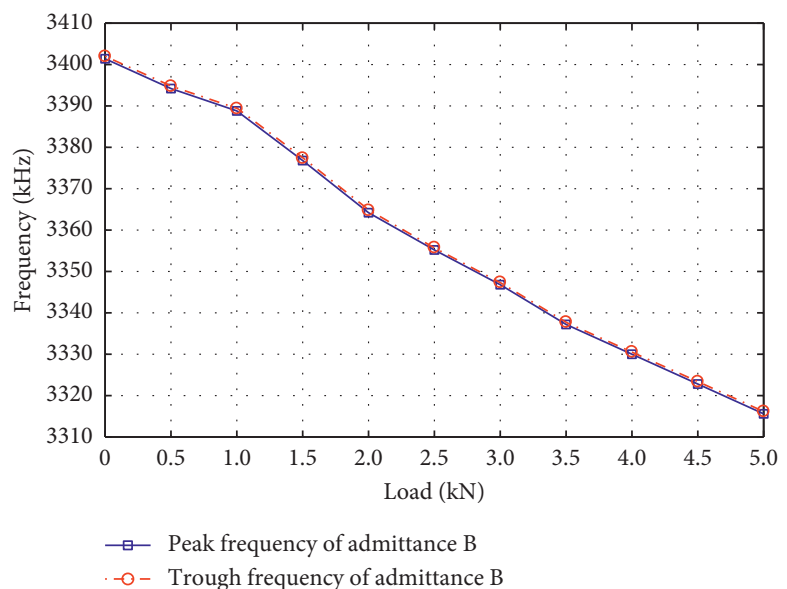

FIGURE 9: Frequencies corresponding to the peak and trough of the admittance signature between $3300 \mathrm{kHz}$ and $3420 \mathrm{kHz}$ excitation.

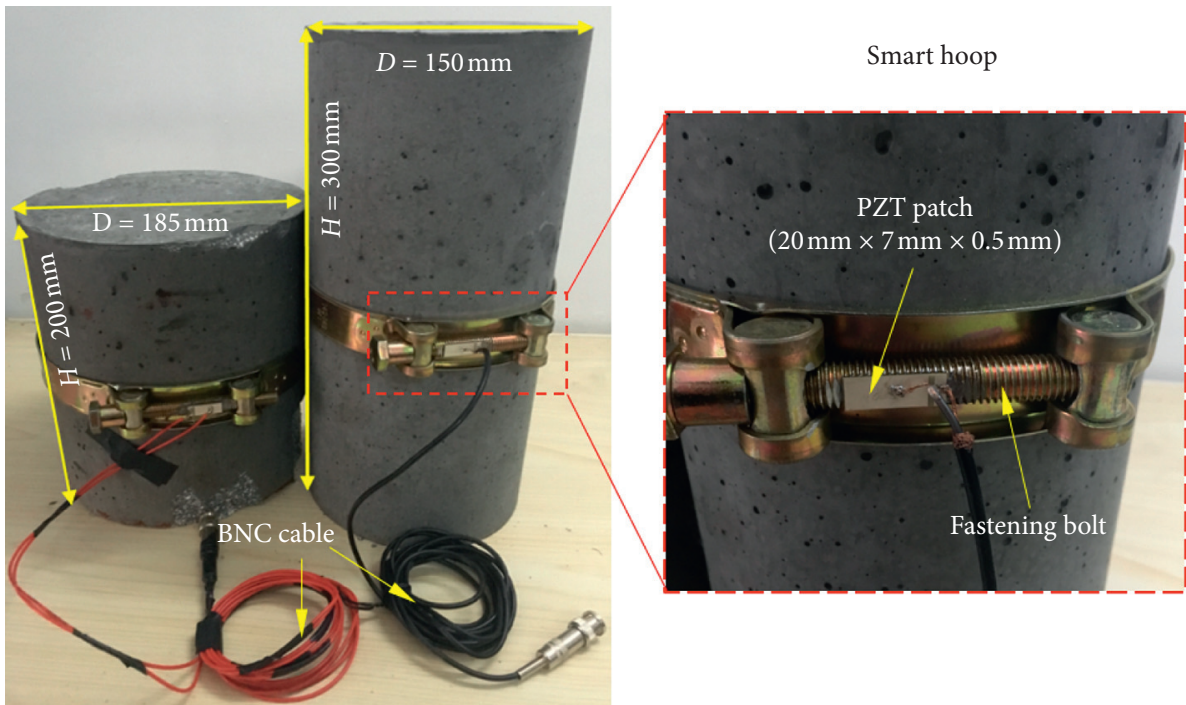

FIGURE 10: Dimensions of the concrete columns and the smart hoop. 


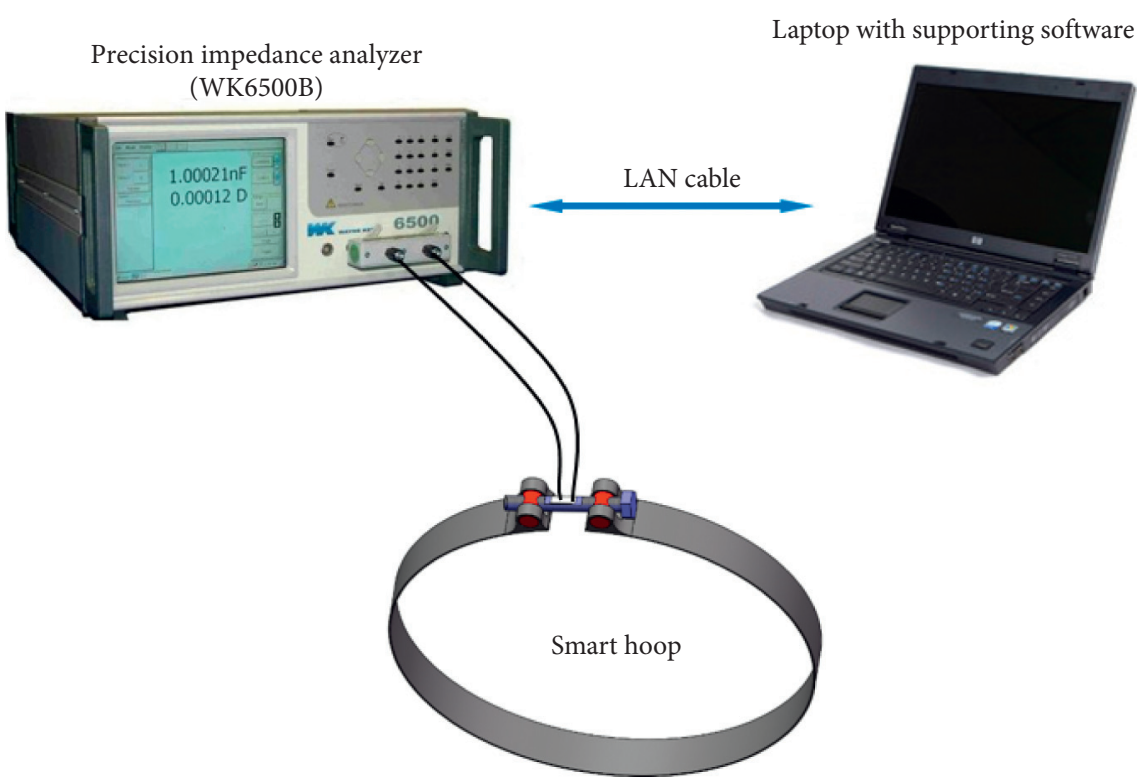

FIGURE 11: Setup of the smart hoop in relation to the impedance analyzer and laptop.

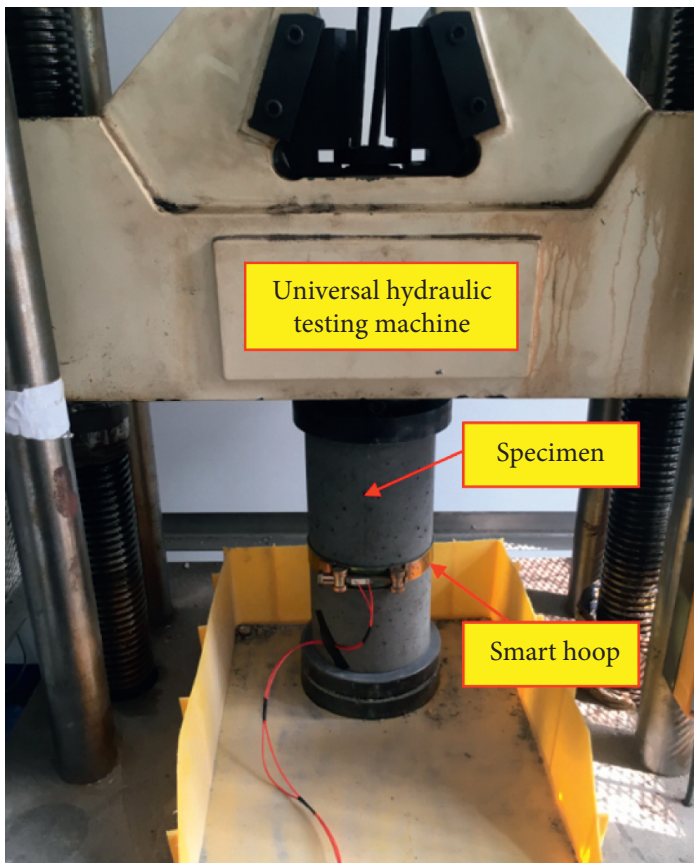

FiguRE 12: Experimental setup using the universal hydraulic testing machine.

axial loads and demonstrate the ability of the smart hoop to monitor the axial load variation when the hoop is used to measure the shift in the impedance frequency.

5.3. Discussion. In this manuscript, a feasibility study on the wearable smart hoop for the monitoring the axial load variation of concrete columns is conducted. The principle used by the smart hoop is to measure the shift of the impedance frequency of the piezoelectric transducer installed on the smart hoop. The results from both the simplified tension test of a steel plate and the axial compression test of two cylindrical concrete columns are in good agreement. Both tests demonstrate the ability of the coupled piezoelectric transducer to detect changes of the axial load applied on the host structure. In addition, the proposed monitoring indices, that is, the frequencies corresponding to the wave peak and trough of the admittance signal, decrease with the increasing load on the host structure.

However, it should be noted that the relationship between the frequency of the admittance signature and the 


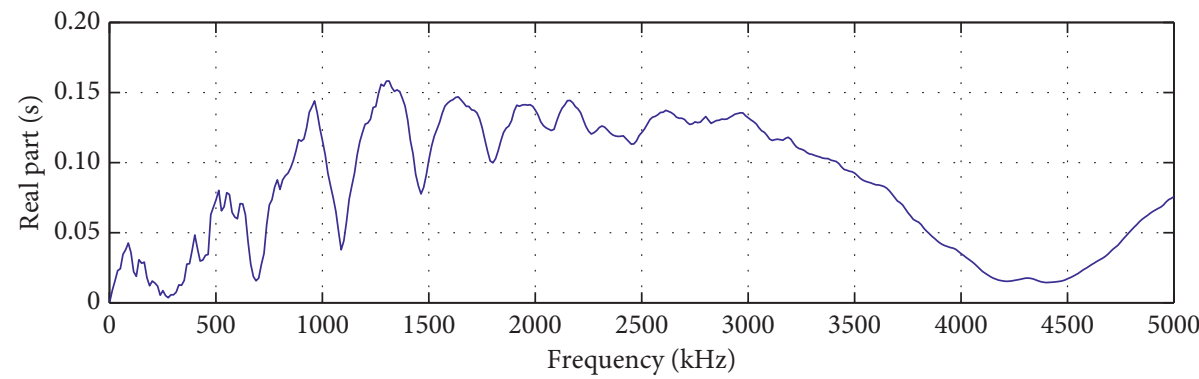

(a)

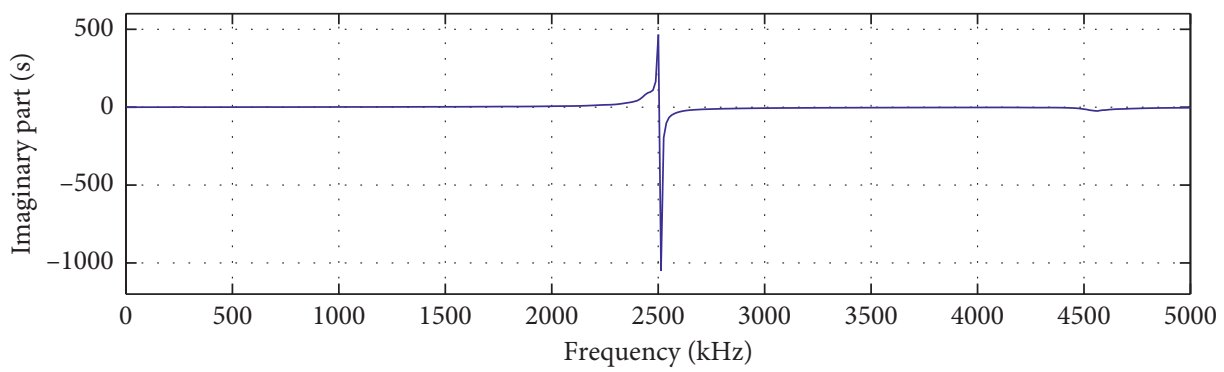

(b)

Figure 13: Admittance characteristics for column \#1.

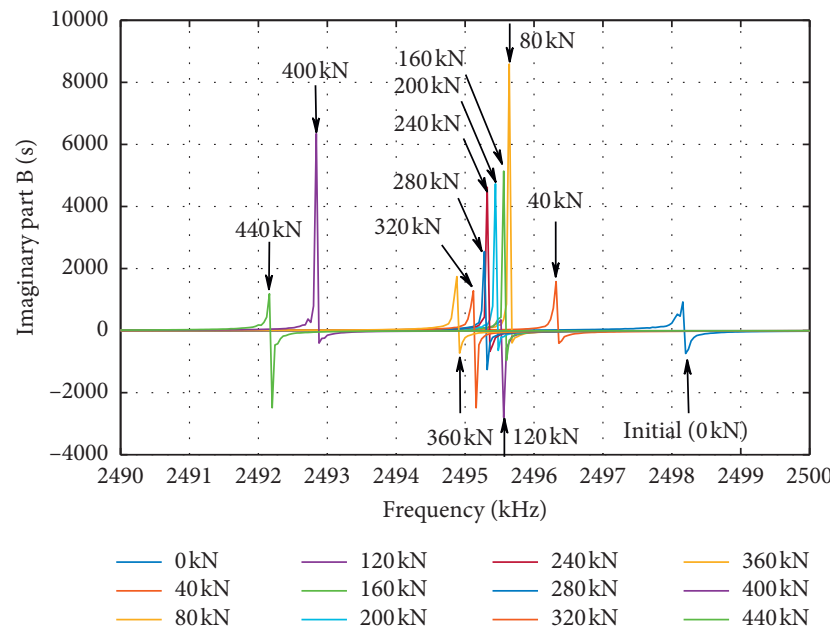

FIgURE 14: Admittance (imaginary part) signatures at different load conditions for column \#1.

applied load on the host structure will require further study, and a more comprehensive equation with a suitable physical interpretation should be derived. Furthermore, only the cylindrical RC columns were employed and investigated in this study to verify the effectiveness of the proposed method. Due to the difference of load-transferring mechanism, the ring-shaped hoop may have been difficult to directly identify the axial load variation for square or rectangular columns; thus a significant improvement for the smart hoop may be needed and require further research in the future work. The lamb wave propagation and final detection results of the smart hoop will also be influenced by other factors, including thermal stress, moisture, environmental pressure,

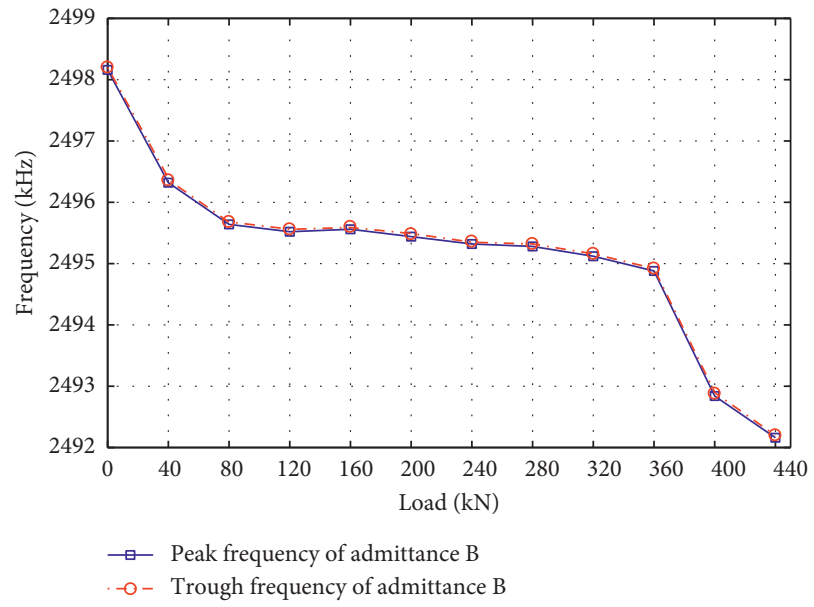

FIGURE 15: Frequencies of the peak and trough in the admittance signature for column \#1.

sensor location, and structural materials. Several researchers have experimentally verified that changing the ambient temperature will induce differences in EMI-based detection results, including magnitude changes or frequency shifts in the measured impedance signatures $[45,46]$. Finally, the current study is limited to small scale, cylindrical concrete columns. Therefore, future work should be performed on larger scale columns in preparation for practical deployment.

On the other hand, the usefulness of the proposed smart hoop can not only be limited in the area of load variation monitoring for RC columns; this detection principle and smart hoop can also be employed to evaluate the degradation phenomenon, such as the corrosion of the reinforcement 


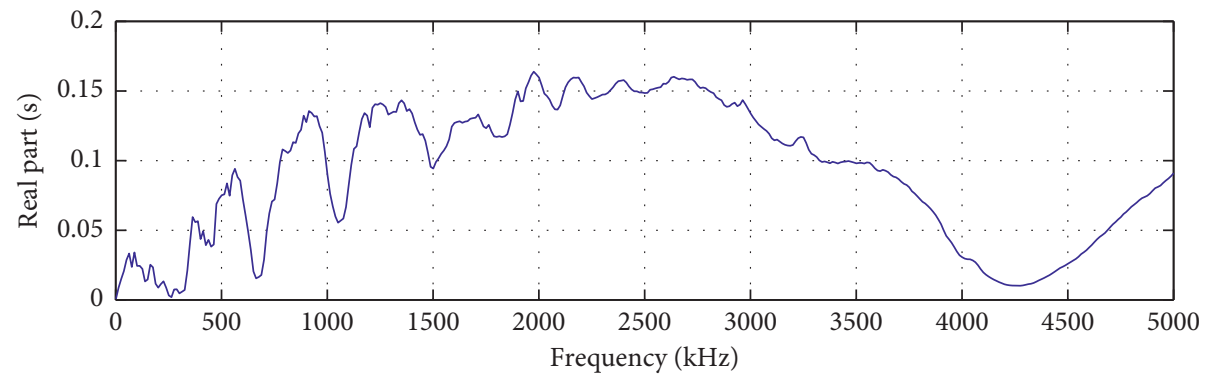

(a)

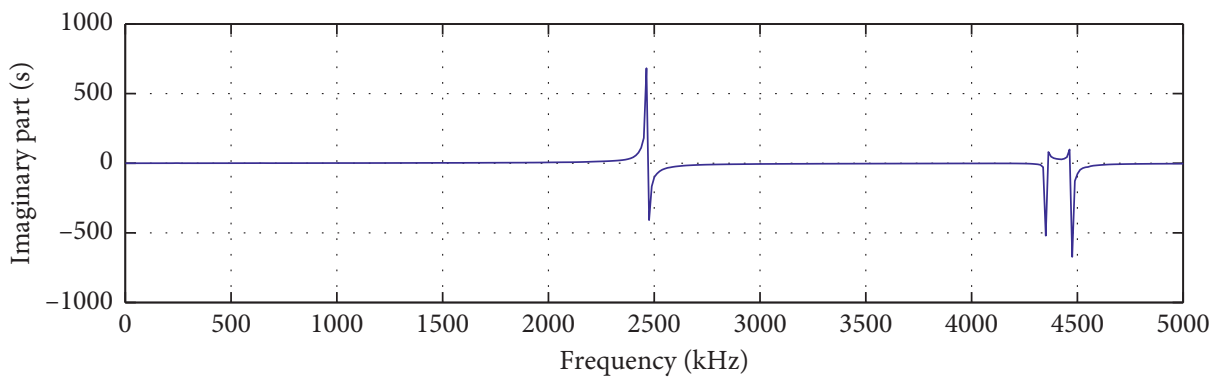

(b)

FIGURE 16: Scan results of the admittance for column \#2.

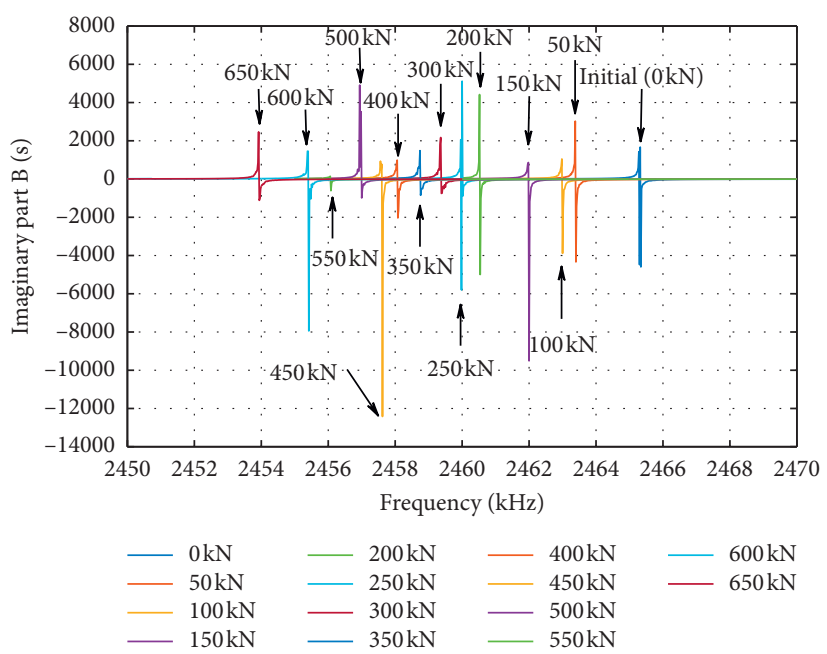

Figure 17: Admittance signatures at different load conditions for column \#2.

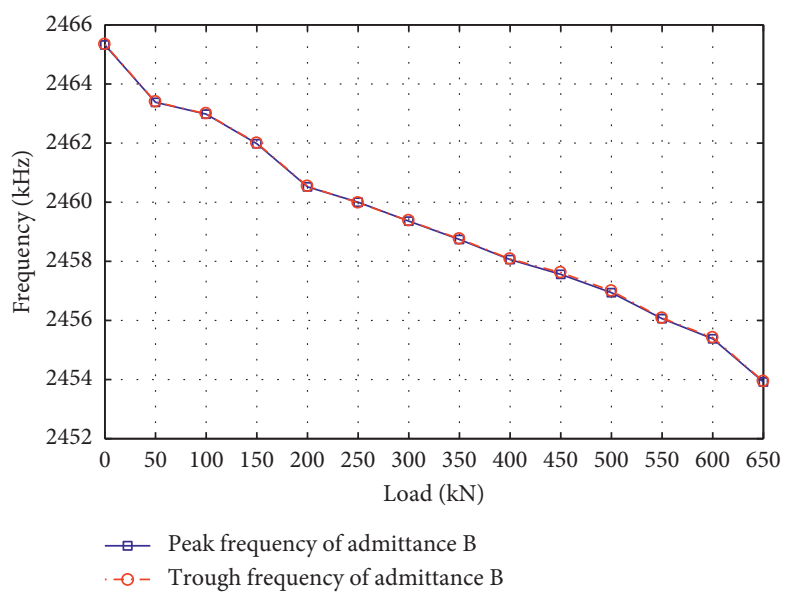

Figure 18: Frequencies corresponding to the peak and trough of the admittance signature for specimen \#2. 
bars in concrete columns [47-49]. In the next works, one of the research topics is to investigate and validate the feasibility of the proposed method in the area of the strength evaluation of deteriorated $\mathrm{RC}$ structures.

\section{Conclusions}

In this study, a wearable smart hoop is proposed to monitor axial load variation for the cylindrical columns through the measurement of shifts in the impedance frequency of the piezoelectric transducer that bonded on the hoop. In order to validate the feasibility of the wearable smart hoop, a simplified tension test involving a piezoelectric transducer bonded to steel plate is carried out to examine the behavior of the piezoelectric transducer's impedance frequency when the steel plate is tensioned. Then, two cylindrical concrete columns with different dimensions are poured and subjected to axial compression tests while equipped with the smart hoop. All the experimental results presented a significant leftward (i.e., downwards) frequency shift for the imaginary part of the admittance signal when the load increases. The proposed loading monitoring indices (i.e., the frequencies corresponding to the wave peak and trough of the admittance signal) shared a similar tendency to drop with the increase of axial load on the tested column. Therefore, a conclusion can be drawn that the wearable smart hoop has the potential to follow axial loading variation on existing concrete columns by analyzing the frequency shift of the measured admittance signal.

\section{Data Availability}

All data included in this study are available upon request by contact with the corresponding author (e-mail: fengqian@ eqhb.gov.cn) or the first author (e-mail: ybliang2010@ hotmail.com).

\section{Conflicts of Interest}

The authors declare that there are no conflicts of interest regarding the publication of this paper.

\section{Acknowledgments}

This research was partially supported by the Science for Earthquake Resilience of China Earthquake Administration (Grant no. XH19031Y), the National Natural Science Foundation of China (Grants nos. 51708520 and 51878628), and the Scientific Research Fund of Institute of Seismology and Institute of Crustal Dynamics, China Earthquake Administration (Grant no. IS201626258). The authors would like to acknowledge them for their financial support.

\section{References}

[1] M. F. Ferrotto, O. Fischer, and L. Cavaleri, "A strategy for the finite element modeling of FRP-confined concrete columns subjected to preload," Engineering Structures, vol. 173, pp. 1054-1067, 2018.
[2] M. F. Ferrotto, L. Cavaleri, and M. Papia, "Compressive response of substandard steel-jacketed RC columns strengthened under sustained service loads: from the local to the global behavior," Construction and Building Materials, vol. 179, pp. 500-511, 2018.

[3] M. F. Ferrotto, O. Fischer, and L. Cavaleri, "Analysis-oriented stress-strain model of CRFP-confined circular concrete columns with applied preload," Materials and Structures, vol. 51, p. 44, 2018.

[4] M. F. Ferrotto, O. Fischer, and R. Niedermeier, "Experimental investigation on the compressive behavior of short-term preloaded carbon fiber reinforced polymer-confined concrete columns," Structural Concrete, vol. 19, no. 4, pp. 988-1001, 2018.

[5] A. Behnia, H. K. Chai, and T. Shiotani, "Advanced structural health monitoring of concrete structures with the aid of acoustic emission," Construction and Building Materials, vol. 65, pp. 282-302, 2014.

[6] W. Li, S. C. M. Ho, D. Patil, and G. Song, "Acoustic emission monitoring and finite element analysis of debonding in fiberreinforced polymer rebar reinforced concrete," Structural Health Monitoring, vol. 16, no. 6, pp. 674-681, 2017.

[7] W. Li, Q. Kong, S. C. M. Ho, I. Lim, Y. L. Mo, and G. Song, "Feasibility study of using smart aggregates as embedded acoustic emission sensors for health monitoring of concrete structures," Smart Materials and Structures, vol. 25, no. 11, Article ID 115031, 2016.

[8] C. Koch and I. Brilakis, "Pothole detection in asphalt pavement images," Advanced Engineering Informatics, vol. 25, no. 3, pp. 507-515, 2011.

[9] T. Nishikawa, J. Yoshida, T. Sugiyama, and Y. Fujino, "Concrete crack detection by multiple sequential image filtering," Computer-Aided Civil and Infrastructure Engineering, vol. 27, no. 1, pp. 29-47, 2012.

[10] M.-K. Kim, H. Sohn, and C.-C. Chang, "Localization and quantification of concrete spalling defects using terrestrial laser scanning," Journal of Computing in Civil Engineering, vol. 29, Article ID 04014086, 2015.

[11] M. Majumder, T. K. Gangopadhyay, A. K. Chakraborty, K. Dasgupta, and D. K. Bhattacharya, "Fibre Bragg gratings in structural health monitoring-Present status and applications," Sensors and Actuators A: Physical, vol. 147, no. 1, pp. 150-164, 2008.

[12] W. Li, C. Xu, S. Ho, B. Wang, and G. Song, "Monitoring concrete deterioration due to reinforcement corrosion by integrating acoustic emission and FBG strain measurements," Sensors, vol. 17, no. 3, p. 657, 2017.

[13] S. C. M. Ho, W. Li, B. Wang, and G. Song, "A load measuring anchor plate for rock bolt using fiber optic sensor," Smart Materials and Structures, vol. 26, Article ID 057003, 2017.

[14] S. C. M. Ho, L. Ren, H.-N. Li, and G. Song, "A fiber Bragg grating sensor for detection of liquid water in concrete structures," Smart Materials and Structures, vol. 22, Article ID 055012, 2013.

[15] G. Song, H. Gu, Y. L. Mo, T. T. C. Hsu, and H. Dhonde, "Concrete structural health monitoring using embedded piezoceramic transducers," Smart Materials and Structures, vol. 16, no. 4, pp. 959-968, 2007.

[16] G. Song, H. Gu, and Y.-L. Mo, "Smart aggregates: multifunctional sensors for concrete structures-a tutorial and a review," Smart Materials and Structures, vol. 17, Article ID 033001, 2008.

[17] Q. Kong, H. Chen, Y.-1. Mo, and G. Song, "Real-time monitoring of water content in sandy soil using shear mode 
piezoceramic transducers and active sensing-A feasibility study," Sensors, vol. 17, no. 10, p. 2395, 2017.

[18] Q. Kong, R. Robert, P. Silva, and Y. Mo, "Cyclic crack monitoring of a reinforced concrete column under simulated pseudo-dynamic loading using piezoceramic-based smart aggregates," Applied Sciences, vol. 6, no. 11, p. 341, 2016.

[19] Q. Feng, Q. Kong, L. Huo, and G. Song, "Crack detection and leakage monitoring on reinforced concrete pipe," Smart Materials and Structures, vol. 24, no. 11, p. 115020, 2015.

[20] Q. Feng, Q. Kong, J. Jiang, Y. Liang, and G. Song, "Detection of interfacial debonding in a rubber-steel-layered structure using active sensing enabled by embedded piezoceramic transducers," Sensors, vol. 17, no. 9, p. 2001, 2017.

[21] L. Huo, D. Chen, Y. Liang, H. Li, X. Feng, and G. Song, "Impedance based bolt pre-load monitoring using piezoceramic smart washer," Smart Materials and Structures, vol. 26, Article ID 057004, 2017.

[22] S. Fan, W. Li, Q. Kong, Q. Feng, and G. Song, "Monitoring of pin connection loosening using eletromechanical impedance: numerical simulation with experimental verification," Journal of Intelligent Material Systems and Structures, vol. 29, no. 9, pp. 1964-1973, 2018.

[23] Y. Liang, D. Li, S. M. Parvasi, Q. Kong, and G. Song, "Bondslip detection of concrete-encased composite structure using electro-mechanical impedance technique," Smart Materials and Structures, vol. 25, Article ID 095003, 2016.

[24] Y. Liang, Q. Feng, D. Li, and S. Cai, "Loosening monitoring of a threaded pipe connection using the electro-mechanical impedance technique-experimental and numerical studies," Sensors, vol. 18, no. 11, p. 3699, 2018.

[25] C.-W. Ong, Y. Yang, A. S. K. Naidu, Y. Lu, and C. K. Soh, "Application of the electro-mechanical impedance method for the identification of in-situ stress in structures," Smart Structures, Devices, and Systems, vol. 4935, pp. 503-515, 2002.

[26] Y. Y. Lim and C. K. Soh, "Effect of varying axial load under fixed boundary condition on admittance signatures of electromechanical impedance technique," Journal of Intelligent Material Systems and Structures, vol. 23, no. 7, pp. 815-826, 2012.

[27] J. Shao, T. Wang, H. Yin, D. Yang, and Y. Li, "Bolt looseness detection based on piezoelectric impedance frequency shift," Applied Sciences, vol. 6, no. 10, p. 298, 2016.

[28] Y. Liang, D. Li, S. M. Parvasi, and G. Song, "Load monitoring of pin-connected structures using piezoelectric impedance measurement," Smart Materials and Structures, vol. 25, no. 10, Article ID 105011, 2016.

[29] T. Wang, D. Wei, J. Shao, Y. Li, and G. Song, "Structural stress monitoring based on piezoelectric impedance frequency shift," Journal of Aerospace Engineering, vol. 31, Article ID 04018092, 2018.

[30] T. Liu, D. Zou, C. Du, and Y. Wang, "Influence of axial loads on the health monitoring of concrete structures using embedded piezoelectric transducers," Structural Health Monitoring: An International Journal, vol. 16, no. 2, pp. 202-214, 2017.

[31] Z. Wang, D. Chen, L. Zheng, L. Huo, and G. Song, "Influence of axial load on electromechanical impedance (emi) of embedded piezoceramic transducers in steel fiber concrete," Sensors, vol. 18, no. 6, p. 1782, 2018.

[32] C. Liang, F. P. Sun, and C. A. Rogers, "Coupled electromechanical analysis of adaptive material systems-determination of the actuator power consumption and system energy transfer," Journal of Intelligent Material Systems and Structures, vol. 8, no. 4, pp. 335-343, 1997.
[33] G. Park, H. H. Cudney, and D. J. Inman, "An integrated health monitoring technique using structural impedance sensors," Journal of Intelligent Materials Systems and Structures, vol. 11, no. 6, pp. 448-455, 2000.

[34] G. Park, H. H. Cudney, and D. J. Inman, "Feasibility of using impedance-based damage assessment for pipeline structures," Earthquake Engineering \& Structural Dynamics, vol. 30, no. 10, pp. 1463-1474, 2001.

[35] X. Hu, H. Zhu, and D. Wang, "A study of concrete slab damage detection based on the electromechanical impedance method," Sensors, vol. 14, no. 10, pp. 19897-19909, 2014.

[36] D. Wang, H. Song, and H. Zhu, "Electromechanical impedance analysis on piezoelectric smart beam with a crack based on spectral element method," Mathematical Problems in Engineering, vol. 2015, Article ID 713501, 13 pages, 2015.

[37] W. Na and J. Baek, "A review of the piezoelectric electromechanical impedance based structural health monitoring technique for engineering structures," Sensors, vol. 18, no. 5, p. 1307, 2018.

[38] S. Fan, S. Zhao, B. Qi, and Q. Kong, "Damage evaluation of concrete column under impact load using a piezoelectricbased EMI technique," Sensors, vol. 18, no. 5, p. 1591, 2018.

[39] V. Giurgiutiu and C. Rogers, "Electro-mechanical (E/M) impedance method for structural health monitoring and nondestructive evaluation," in Proceedings of the International Workshop on Structural Health Monitoring-Current Status and Perspective, pp. 18-20, Stanford, CA, USA, September 1997.

[40] Q. Meng, M. Zhang, L. Han, H. Pu, and H. Li, "Effects of size and strain rate on the mechanical behaviors of rock specimens under uniaxial compression," Arabian Journal of Geosciences, vol. 9, p. 527, 2016.

[41] X. X. He, S. Y. Lin, and X. C. Zhen, "Experimental study on size effect of compressive strength and deformation properties of large size fly ash concrete," Key Engineering Materials, vol. 477, pp. 319-324, 2011.

[42] F. G. Baptista and J. V. Filho, "Optimal frequency range selection for PZT transducers in impedance-based SHM systems," IEEE Sensors Journal, vol. 10, no. 8, pp. 1297-1303, 2010.

[43] S. Safour and Y. Bernard, "Static force transducer based on resonant piezoelectric structure: root cause investigation," Smart Materials and Structures, vol. 26, Article ID 055012, 2017.

[44] V. G. M. Annamdas, Y. Yang, and C. K. Soh, "Influence of loading on the electromechanical admittance of piezoceramic transducers," Smart Materials and Structures, vol. 16, no. 5, pp. 1888-1897, 2007.

[45] F. Baptista, D. Budoya, V. Almeida, and J. Ulson, “An experimental study on the effect of temperature on piezoelectric sensors for impedance-based structural health monitoring," Sensors, vol. 14, no. 1, pp. 1208-1227, 2014.

[46] T. Wandowski, P. H. Malinowski, and W. M. Ostachowicz, "Delamination detection in CFRP panels using EMI method with temperature compensation," Composite Structures, vol. 151, pp. 99-107, 2016.

[47] M. M. Kashani, A. J. Crewe, and N. A. Alexander, "Stressstrain response of corroded reinforcing bars under monotonic and cyclic loading," in Proceedings of the 15th World Conference of Earthquake Engineering, p. 590, Lisbon, Portugal, September 2012.

[48] M. Tapan and R. S. Aboutaha, "Strength evaluation of deteriorated RC bridge columns," Journal of Bridge Engineering, vol. 13, no. 3, pp. 226-236, 2008.

[49] G. Campione, F. Cannella, and G. Minafò, "A simple model for the calculation of the axial load-carrying capacity of corroded RC columns," Materials and Structures, vol. 49, no. 5, pp. 1935-1945, 2016. 